\title{
Lessons from thiamin-watching
}

\author{
Ronald Kluger \\ University of Toronto, Department of Chemistry, 80 St. George Street, Toronto, Canada M5S 1A1
}

Abstract: Thiamin is a vitamin that is a catalyst for reactions involving formation of acyl carbanion equivalents. The closely related species, thiamin diphosphate, is associated with enzymes that catalyze the decarboxylation of $\alpha$-ketoacids. While the enzymes attract the ketoacid, thiamin diphosphate adds to it, leading to release of carbon dioxide. Intermediates in the reactions can be synthesized. Kinetic analysis of their reactions reveals what the enzyme overcomes in each step. In the laboratory, thiamin reacts with benzaldehyde to cause a benzoin condensation. In neutral solution, benzaldehyde destroys thiamin.. Analysis of the products and kinetics of destruction reveals the steps by which it occurs: addition and proton transfers followed by a fragmentation step that is itself a mechanistic puzzle.

\section{INTRODUCTION}

This article is in conjunction with the thirteenth IUPAC Conference on Physical Organic Chemistry at Inha University, Inchon, Korea, celebrating the $50^{\text {th }}$ anniversary of the Korean Chemical Society. I join in wishing the Society continued success and thank the organizers for inviting my participation in this event.

Physical organic chemistry has benefited from having interesting problems available within its domain that extend beyond our discipline. The early discovery of vitamins and their role in nutrition made them the subject of medicinal interest. They also became worthy subjects for physical organic investigation. Thiamin, vitamin B1, was one of the first biochemical subjects to which the principles of physical organic chemistry were applied. The structure and properties of the vitamin, the reactions it promotes, and the role of its derivatives in enzymes continue to be subjects of intense study. The work exemplifies the possibilities of physical organic chemistry as a life science.

The establishment of the structure of thiamin (Vitamin B1) and the nearly immediate synthesis was a landmark of organic chemical progress in the 1930's.(ref. 1) The structure gave little in the way of a direct clue as to how it functions in nerve action. Later its diphosphate derivative was identified as 'cocarboxylase' a necessity in metabolic decarboxylations in species as diverse as humans and yeast. Only when physical organic chemists started looking at the functional aspects of thiamin was there progress in learning the precise role of the cofactor(ref. 2).

\section{EARLY SIGHTINGS}

A major scientific aspect of the beer-brewing industry has been finding and protecting colonies of yeast with enhanced abilities in converting sugar to ethanol and carbon dioxide. The breakdown of glucose by yeast leads through glycolysis to pyruvate. This goes on to carbon dioxide and acetaldehyde. Reduction of acetaldehyde, promoted by alcohol dehydrogenase, produces ethanol.

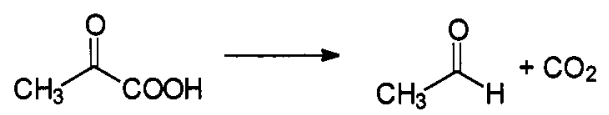

There is no chemical equivalent to the $\alpha$-ketoacid decarboxylation process, yet the yeast do this with routinely. It involves loss of carbon dioxide, a Lewis acid, from the carbonyl group carbon, normally a Lewis acid but in this case behaving as a Lewis base, followed by addition of a proton. A collection of this and related observations led to the conclusion that biochemical reactions that appear to involve the equivalent of an acyl carbanion are promoted by enzymes that utilize thiamin diphosphate (1) as a cofactor. 
<smiles>Cc1ncc(C[n+]2c(C)sc(CCOc3ccccc3)c2C)c(N)n1</smiles>

\section{FINDING THE HIDDEN PATHWAY}

These reactions involve an umpolung of the usual reactivity patterns of carbonyl groups. After a report that thiamin in the absence of an enzyme could catalyze the decarboxylation of pyruvate, the mechanism became accessible as a chemical problem (ref. 3). Soon, Breslow, in a pioneering application of proton $\mathrm{nmr}$, reported the site and rate of exchange reactions of a thiazolium compound related to thiamin (ref. 4,5 , 6). From the information in those studies, he proposed that 1 makes possible a route in which reasonable intermediates can be generated that lead to the product, through normal acid-base chemistry. The reaction proceeds via the ylide (2) which is the conjugate base of 1 . This adds to pyruvate and, after appropriate proton transfers, forms the intermediate 2-(2-lactyl)-thiamin diphosphate (으).

1

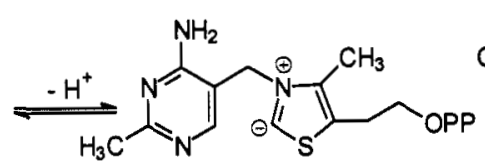

2

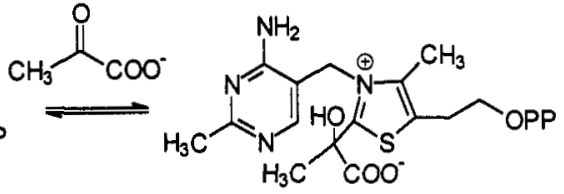

$\underline{3}$

The intermediate should lose carbon dioxide more readily than any precursor. $\mathrm{As} \mathrm{CO}_{2}$ departs, the residual electron density is accommodated as an enamine (4). Protonation leads to formation of a stable species, 2-(1-hydroxyethyl thiamin diphosphate), $\underline{\mathbf{5}}$. This species was later isolated from pyruvate decarboxylase by Krampitz. He showed that addition of $\underline{5}$ to the enzyme lacking 1 (and thus inactive) led to the release of acetaldehyde and the regaining of enzymic activity.

$\underline{3}$

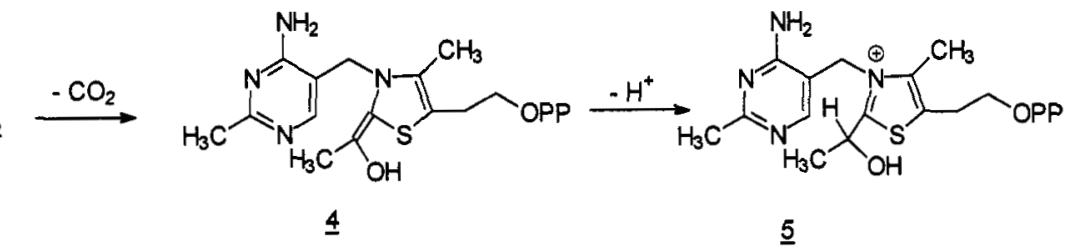

Breslow's mechanism was unexpected but obviously correct. It was immediate acclaimed, and is cited in almost every text as an example of chemical insight into a biochemical problem. This work inspired the development of thiazolium compounds as catalysts in synthetic processes requiring acyl carbanion equivalents. Of course it also provided an approach for detailed studies of related enzymic reaction mechanisms.

\section{SOURCES OF ACCELERATION}

The mechanism explains what is happening but it did not fully explain how the enzyme actually performs its tasks. Lienhard found that in a simplified model of $\underline{3}$, the rate constant for decarboxylation in water is many orders of magnitude smaller than the catalytic rate constant of the enzyme. However, in less polar solvents, the rate constant approaches that of the enzyme (ref. 7). It was concluded that the enzyme accelerates the reaction by placing $\underline{3}$ in a nonpolar environment. However, since $\underline{3}$ is hydrophilic, any faster reaction in a hydrophobic environment is countered by the cost in desolvation from water. As useful as the model system was, it was also important to make $\underline{3}$ itself and determine its reactivity with and without the enzyme.

\section{FINDING THE INTERMEDIATES}

Tim Smyth in our laboratory developed a convenient synthetic route to the parent alcohol of $\underline{3}, 2$-(2-lactyl thiamin) (ㅁ) and to $\underline{3}$ itself (ref. 8). The kinetics and reaction patterns of $\underline{3}$ were studied in detail by Jik 
Chin. He found that $\underline{6}$ behaved similarly to Lienhard's model in decarboxylation, with the reaction being faster in organic solvents (ref. 8). However, he also did other important measurements that placed the material into energetic context. Chin carefully followed the reactions of $\underline{3}$, observing that the release of pyruvate is subject to specific base catalysis while the decarboxylation of $\underline{6}$ is not catalyzed by acids or bases. At $\mathrm{pH} \sim 10$, the rate of decarboxylation of $\underline{6}$ equals the rate of conversion of $\underline{6}$ to pyruvate and thiamin ( ( $)$.

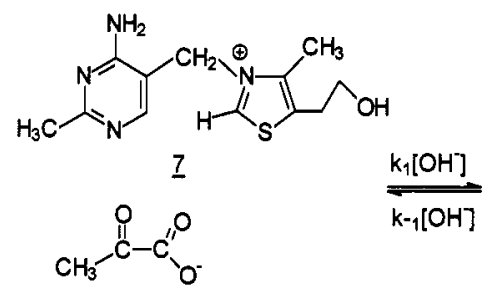
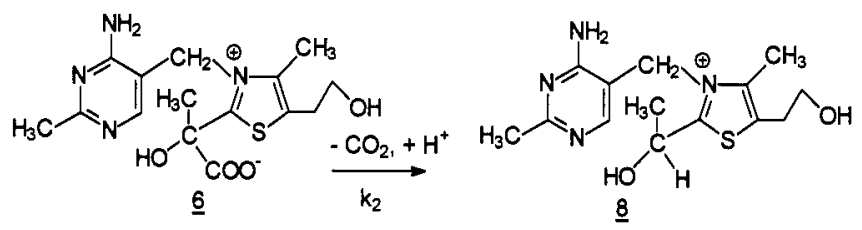

Below $\mathrm{pH} 10$, formation of $\underline{6}$ is rate-determining $\left(\mathrm{k}_{1}\right)$, while at higher $\mathrm{pH}$, the decarboxylation step $\left(\mathrm{k}_{2}\right)$ producing 2-(1-hydroxyethyl)thiamin is rate-determining. The material, in principle can undergo basecatalyzed conversion to thiamin and acetaldehyde but the reaction typically gives further reaction products. A mechanism consistent with specific base catalysis from $\underline{6}$ to pyruvate and thiamin is transfer of a proton from $\underline{6}$ to hydroxide, giving the conjugate base in relatively low concentration, since the $\mathrm{pK}_{\mathrm{a}}$ is $>14$. The conjugate base goes on to pyruvate and thiamin ( 7$)$. The ratio of $\underline{Z}$ to its conjugate base ( $\left.\underline{Z}^{\prime}\right)$ depends only on $\mathrm{pH}$. Thus, Chin found the rate and equilibrium constant for each step in the conversion of pyruvate and thiamin to $\underline{8}$.<smiles></smiles>

$\underline{6}$<smiles></smiles>

$\underline{7}^{\prime}$

Since the enzymic reaction can be expected to involve the analogous set of covalent intermediates derived from the diphosphate, watching thiamin permits a detailed step-by-step comparison with the enzymic reaction. This is especially informative since a cofactor that forms covalent intermediates can undergo the conversions in the absence of enzyme. Most enzymes do not involve covalent intermediates derived from cofactors so they do not have a readily accessible basis for comparison. Furthermore, most cofactors are unlike thiamin diphosphate in that they do not promote reactions on their own.

One surprising result from Chin's work is the discovery of the magnitude of the equilibrium constant relating thiamin, pyruvate and 6 . The derived value for $k_{1} / k_{-1}$ is $\sim 1$. Since this involves a bimolecular state on the reactant side of the equilibrium, a large component is the unfavourable entropy associated with such a process. The translational entropy of two species is reduced to that of one. The same process in an intramolecular situation would have an effective molarity of about $10^{8} \mathrm{M}$ (ref. 9). On an enzyme, where the materials are reduced in entropy by their specific binding, the formation of $\underline{3}$ would then be highly exergonic, leading to the intermediate being in a potential energy valley with no stabilization provided for the transition state. However, if the enzyme is capable of utilizing the energy made available by the formation of $\underline{3}$ to desolvate it, then catalysis can be efficiently achieved.

Tim Smyth synthesized $\underline{3}$ and attempted to combine it with pyruvate dehydrogenase lacking thiamin diphosphate (ref. 10). The intermediate did not combine with the apoenzyme. Yet various carboxylic esters of $\underline{3}$ and the decarboxylation product $(\underline{5})$ did combine with the apoenzyme. This is consistent with the expectation presented in the previous paragraph. If the enzyme derives its energy for desolvation of $\underline{3}$ from its formation, then addition of exogenous $\underline{3}$ will be prevented since there is no energy source to convert the enzyme into the desolvating form. The other derivatives can bind because they are recognized by the enzyme as materials that are not to be desolvated. This showed how a detailed knowledge of the physical organic facts leads to an understanding of the biochemical system. 


\section{CLOSE-UP OBSERVATION-ISOTOPE EFFECTS}

Another physical organic way to do better thiamin-watching involves the use of kinetic isotope effects. (Since the effects focus on transition states, they can be considered to be the equivalent of binoculars). Again we have the chance to compare in detail the factors on and off the enzyme. Mike Brandl measure the secondary $\beta$ deuterium isotope effects on the decarboxylation of $\underline{6}$ (ref. 11). The magnitude of the isotope effect could then be compared to that of the enzymic reaction in the elegant work of Schowen and his collaborators (ref. 12,13). They have been able to provide a detailed picture of the energetics of pyruvate decarboxylase catalysis from analysis of enzymic and nonenzymic isotope effects on each step.

\section{TRANSITION STATES AND ANALOGUES}

The concept of transition state analogues as potent inhibitors of enzymes was developed in proposals made simultaneously by Lienhard and Wolfenden (ref. 14, 15). The method is based on the principles of transition state theory. A rate constant is directly related to transition state energy. Catalysis involves a route via a lower energy transition state due specific stabilization by an additional agent. In an enzyme, binding energy is used to transform the enzyme to a form in which the transition state is most tightly bound. The transition state will have a higher affinity for the transformed enzyme, causing a net lowering of energy and thus acceleration. A molecule that resembles the transition state more closely than does the reactant should bind the analogue more tightly than it does the reactant. Thus, Lienhard had proposed that thiamin thiazolone diphosphate ( $\underline{9})$ will serve as an analogue of the transition state associated with conversion of $\underline{3}$ to $\underline{4}$ (ref. 16).<smiles>Cc1ncc(Cn2c(C)c(CCOc3ccccc3)sc2=O)c(N)n1</smiles>

$\underline{9}$

This does bind much more tightly to the apoenzyme than does thiamin diphosphate. This was an early successful design of an enzyme inhibitor based on thoughts derived from the theory of transition state analogues. The principles of that method continue to be useful guides for designing inhibitors and for designing antigens for producing catalytic antibodies. However, this aspect of thiamin-watching taught us another lesson. The inhibition does not of itself reveal why it occurs. In developing the theory of transition state analogues, Wolfenden added the caution that if the enzyme stabilizes the transition state by isomerizing to a form that makes the binding site inaccessible (a 'closed' state), then the analogue should not bind (ref. 17). As mentioned above, Tim Smyth had found that the intermediate that most closely resembles the transition state for decarboxylation in pyruvate dehydrogenase ( $\underline{3}$ ) does not bind to the enzyme. This can be understood in terms of the Wolfenden hypothesis concerning in accessibility. Yet, 9 does bind. The conclusion we reached is that $\underline{9}$ must bind tightly for another reason. Since the cofactor must be able to provide catalysis, and thus bind to all forms of the enzyme, its affinity for the initial state of the enzyme is not informative. However, since 9 is not a catalyst, it can bind tightly to the initial form of the enzyme. Gerald Gish and Glen Kauffman studied the relative hydrophobicity of thiamin thiazolone and thiamin as well as the binding their diphosphates to pyruvate decarboxylase. They found that the thiazolone is much more hydrophobic than thiamin so $\underline{8}$ could be expected to have higher affinity if the cofactor binding site is hydrophobic. In the enzyme, the affinity difference is matched by the hydrophobicity (ref. 18).

\section{SEEING BETTER THROUGH CRYSTALS}

Crystallography is an excellent way to do thiamin-watching. Since thiamin is relatively small, the detailed crystal structure has been available and can be compared to that of its derivatives. When Pletcher and his collaborators in Pittsburgh observed the structure of the phosphonate analogue of $\underline{6}$ by $x$-ray crystallography (since $\underline{6}$ itself is not sufficiently stable) they found that that the $\mathrm{C}(2 \alpha)$-P bond is perpendicular to the plane of the thiazolium ring (ref. 19). While this was an unprecedented conformation, if one envisions the carboxyl in the same position, this is precisely the orientation needed for the transition state in the breaking of $\mathrm{C}-\mathrm{C}$ bond during decarboxylation. 


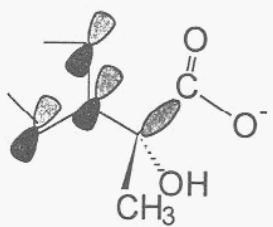

Shin and coworkers in Seoul have demonstrated the most extensive case of thiamin-watching and the lessons one can learn (ref. 20). They combined molecular mechanics with information from crystallography that shows the importance of detailed knowledge of conformation to understand biological catalysis.

\section{THIAMIN DIPHOSPHATE IN ENZYME CRYSTALS}

A major breakthrough in learning from thiamin is to be able to find how it looks in its natural surroundings, either in solution or in an enzyme. Shin's work establishes the basis for looking at thiamin in solution. The enzymic environment has become available through major breakthroughs in crystallography. The first thiamin diphosphate enzyme whose structure was determined at high resolution is transketolase, as reported by Lindqvist and Schneider (ref. 21, 22). The structure has many interesting features that relate to the mechanistic considerations we have discussed. The coenzyme is exposed to solution only at the site where the substrate must add, C2'. The detailed conformation of thiamin diphosphate on the enzyme is also available from the structure of the whole protein! The structure shows that amino group of the pyrimidine of the cofactor is almost certainly involved in removal of the proton at C2'. This requires tautomerization and transfer of the proton via a relay system. In relation to the question of the binding of $\underline{8}$ to these enzymes, these workers showed that the material binds well into the hydrophobic pocket in the active site. The structure of pyruvate decarboxylase was the next reported the groups of Furey and Jordan (ref. 23). There is considerable similarity with the transketolase structure with respect to the binding of the cofactor as well as that of pyruvate oxidase but many differences where catalysis involving the substrates occurs (ref. 24). More recently Petsko, Ringe, and Hasson, and their collaborators have solved the structure of benzoylformate decarboxylase in detail. This structure, while similar to that of pyruvate decarboxylase, has very notable and instructive differences (ref. 25). The reaction promoted by that enzyme is shown below.<smiles>O=Cc1ccccc1</smiles>

\section{REALITY MEASUREMENTS}

With all these results, the 'mainstream behaviour' of thiamin in catalysis seemed in good hands. Important details such as the acidity of the $\mathrm{C} 2$ ' $\mathrm{H}$ position of the thiazolium ring was finally settled by the physical organic studies Washabaugh and Jencks (ref. 26). This had been a major puzzle for thiamin watchers. Based on exchange rates, one could estimate the $\mathrm{pK}_{\mathrm{a}}$ as $\sim 18$ or higher. Yet a report of rapid scan, quench experiments gave a $\mathrm{pK}_{\mathrm{a}}$ as low as 13 . This value is unreasonably low for the proposed site and may have resulted from another equilibrium being measured. Jencks and Washabaugh by studying proton transfer reactions that the $\mathrm{pK}_{\mathrm{a}}$ is 18 or higher. The acidity of the $\mathrm{C} 2 \alpha$ position also became a measurable quantity when various methods were developed by Bordwell and Jordan to generate the unstable carbanion-enamine in nonaqueous surroudings (ref. 27). Jordan was also able to produce analogues of the intermediate in enzymic reactions and study their binding to the enzyme (ref. 28).

\section{SOLVING THE (HYDROXYBENZYL)THIAMIN PUZZLE}

Washabaugh studied catalysis of the conversion of 2-(1-hydroxybenzyl)thiamin ( 9 ) to thiamin and benzaldehyde. 
<smiles>Cc1ncc(C[C@@H]2C(CO)=C(CO)S[C@H]2C(O)(c2ccccc2)c2ccccc2)c(N)n1</smiles>

Based on what Jik Chin had learned in studying catalysis of to thiamin and pyruvate, we expect the reaction to specific base catalyzed (ref. 8). The steps we expected from $\underline{10}$ are shown below.<smiles></smiles><smiles>Cc1ncc(C[C@H](Cc2ccccc2)c2sc(CO)c(C)[n+]2C)c(N)n1</smiles><smiles>Cc1ncc(C[n+]2csc(CO)c2C)c(N)n1</smiles>

Crane and Washabaugh reported that the reaction is subject to general base catalysis with a slope less than unity (ref. 29). In order to observe such catalysis, a proton must be transferred in the transition state of the rate-determining (probably concerted with a process involving formation or breaking of bonds between heavier elements). The ionization of the hydroxyl of the reactant should not be rate-determining since the un-ionized form is present in the quantity in which it is added and proton transfer to hydroxide should have a rate constant just below that for diffusion. The protonation of the ylide form of thiamin (11) to produce thiamin should also be rapid, although the concentration of the ylide is relatively small, the rate constant is large. Furthermore, there is no site to which the proton can reasonably add in a aconcerted process. However, the step in which the $\mathrm{C}-\mathrm{C}$ bond breaks in the conjugate base of 10 should be rate-determining while the protonation of that intermediate is very fast, so that the second step in the sequence is ratedetermining. Then why was buffer catalysis observed? It was proposed that the rate-determining step involves protonation of the incipient ylide by a Bronsted acid. But this would mean that the ylide must ne too unstable to exist. Yet, this should not be the case since it is involved in proton exchange reactions. The reported measurements of that reaction had been done by an indirect method (forming a carbonyl derivative of the product) and the method of initial rates. Could the catalysis be associated with the detection method?

\section{KIM'S DISCOVERY}

I presented this set of information to Cheon-Sook Kim, a visiting scholar in Toronto from Korea. Kim carefully studied the reaction by direct measurement using uv spectroscopy. Kim found that under the conditions where general base catalysis was observed 10 undergoes an apparent internal redox reaction in which the $\mathrm{C} 2 \alpha$ position of the hydroxybenzyl sidechain is oxidized to give a phenyl thiazole ketone (2-(1hydroxybenzyl)-5-(2-hydroxyethyl)-4-methylthiazole, (13) while the $\mathrm{C}-\mathrm{N}$ bond to the thiazolium nitrogen is reductively cleaved to give the 2,5-dimethyl-4-amino-1,3-pyrimidine (12).(ref. 30,31) These products had previously been reported by Oka from the reaction of thiamin with benzaldehyde in methanol containing triethylamine.(ref. 32) 
<smiles>Cc1ncc(C[n+]2c(C(O)c3ccccc3)sc(CCO)c2C)c(N)n1</smiles>

$\underline{10}$<smiles></smiles>

$\underline{12}$<smiles>Cc1nc(C(=O)c2ccccc2)sc1CO</smiles>

$\underline{13}$

\section{LOOKING AT BENZOYLFORMATE DECARBOXYLASE}

This fragmentation destroys thiamin, preventing any catalysis by thiamin of reactions such as the benzoin condensation in neutral solution. In contrast, the enzyme benzoylformate decarboxylase must promote the decarboxylation of 2-mandelyl-thiamin diphosphate formed during catalysis in neutral solution.(ref. 33,34$)$ Benzaldehyde is released, permitting recycling of enzyme-bound cofactor.

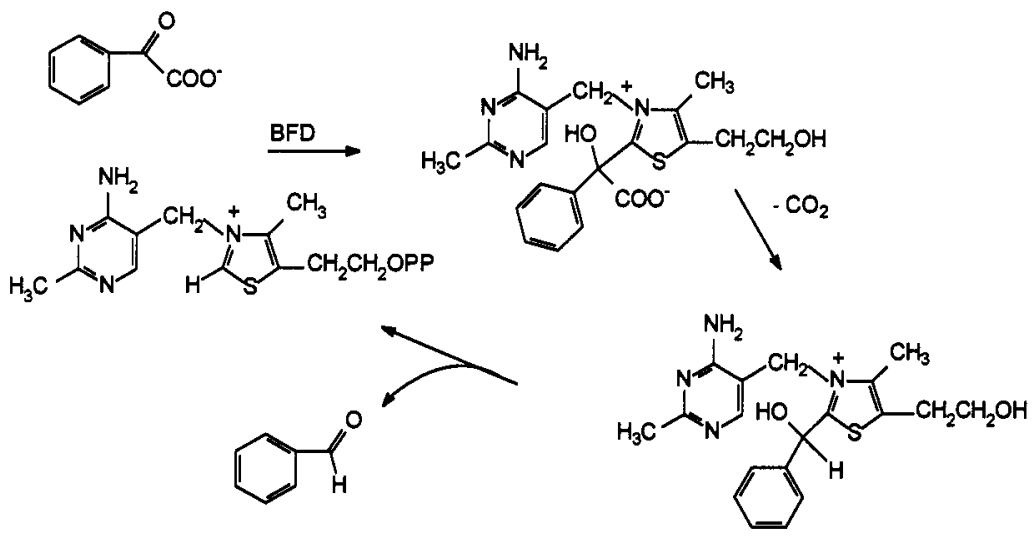

The enzyme can avoid fragmentation by specifically directing catalytic groups to places that promote elimination. There must be points where the mechanisms for fragmentation and elimination differ. The enzyme should have catalytic groups that are arayed to avoid fragmentation. So in order to interpret the enzyme's structure, we need to know the mechanism of the fragmentation reaction in order to know how to avoid it.

\section{SEARCHING FOR THE FRAGMENTATION MECHANISM}

Kim found conditions where the fragmentation reaction could be followed continuously by uv spectroscopy (Fig. 1).(ref. 30)

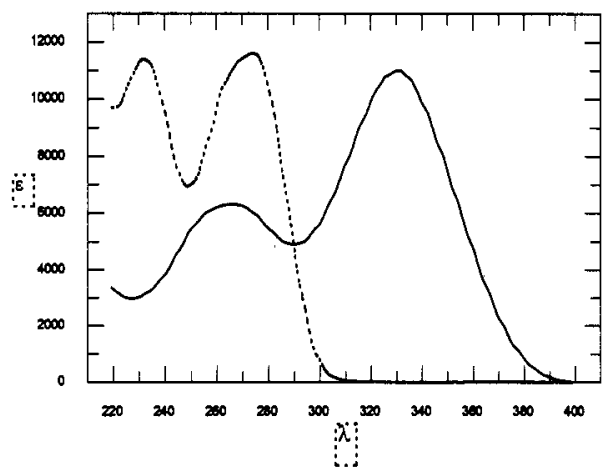

Fig. 1 UV-spectra of $\underline{10}$ (dashed line) and $\underline{13}$ (solid line). 
The course of the fragmentation reaction could even be followed in the presence of the "normal' reaction that produces thiamin and benzaldehyde by elimination. John Lam extended the work to include a full kinetic study, including $\mathrm{pH}$-dependence. Lam followed the change in absorbance at $330 \mathrm{~nm}$. In solutions more basic than $\mathrm{pH} 7$, fragmentation competes with elimination of benzaldehyde.(ref. 30)

We proposed that the fragmentation occurs by a base catalyzed reaction of the $\mathrm{N} 1$ '-protonated conjugate acid of 10.(ref. 30) If the fragmentation is about 100 times faster than elimination in the N1'-protonated species, the fragmentation will predominate at $\mathrm{pH}$ 's up to $\sim 2$ units above the point where $\mathrm{pH}=\mathrm{pK}$. At higher $\mathrm{pH}$, reaction is from the species that is not protonated on N1'. Although we can propose an overall mechanism from these and other data, the pH-dependence is difficult to interpret in detail without knowing if the reaction occurs through a minor tautomer.

\section{WORKING WITH A CAPTIVE POSITIVE CHARGE}

Sometimes the species we try to watch are so dynamic that we can't know what we are looking at. So we can build a trap that holds the charge in place while making as little other change as possible. The $\mathrm{N}$-methyl compound derived form a tertiary amine has such a trapped charge. We modeled the N1'protonated species by the analogous compound containing a methyl group at that site (14).(ref. $35 / \mathrm{p} 188$ 190,36 ) If fragmentation occurs readily from this species, N1' likely to be where the proton is located in the rate-determining step.<smiles></smiles>

14

Lam found that 14 gives two products: The first is the same ketone $(\underline{13})$ as from $\underline{10}$. The second is the $\mathrm{N} 1$ '-methyl derivative of the pyrimidine (12) isolated in the fragmentation of 10 .(ref. 36)

The methylated compound (14) fragments at all acidities, not transforming to elimination as does 10 at high $\mathrm{pH}$. The fragmentation is first order in hydroxide and first order in 14 .(ref. 36) The controlling effect of the positive charge on the N1' position of the pyrimidine ring does not lead to stabilizing resonance interactions in the transition state for fragmentation, conjugation of the charge is indirect. The positively charged pyrimidine derivative must promote fragmentation exclusively by an inductive effect.

\section{WATCHING THE FRAGMENTATION PROCESS}

The $\mathrm{C} 2 \alpha$ proton of $\underline{10}$ must be removed to arrive at $\underline{13}$. It is likely that this is the first step in the reaction sequence but it is not-rate determining since we find by nmr that the exchange of the proton for a deuteron is faster than the overall fragmentation. Since the reaction is base-catalyzed, the rate-determining step involves either the $\mathrm{C} 2 \alpha$ conjugate base (enamine) of 10 or a tautomer. Since we also observe buffer catalysis, proton transfer occurs in that step and $\mathrm{C}-\mathrm{N}$ cleavage is either fast or is concerted with proton transfer.

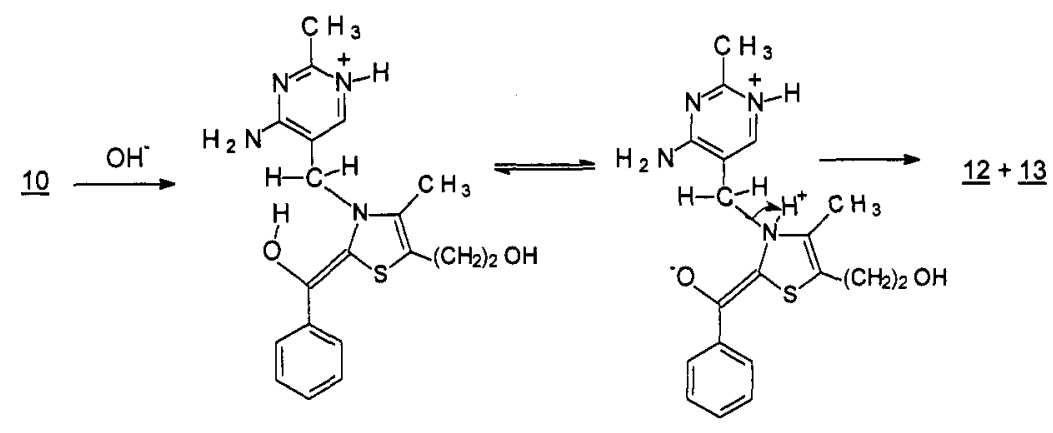


The kinetic data for fragmentation of HBzTh are complicated by the presence of the variability of the protonation state of the pyrimidine. The $\mathrm{pH}$-rate constant profile for fragmentation of fits the equation for titration of a dibasic acid with apparent $\mathrm{pK}_{\mathrm{a}}$ 's of 5.2 and 7.3.(ref. 37) The lower $\mathrm{pK}_{\mathrm{a}}$ corresponds to pyrimidine $\mathrm{N} 1$ '-conjugate acid but the higher kinetic $\mathrm{pK}_{\mathrm{a}}$ must be the result of a rate law that involves a change in rate-determining step. The mechanism above accommodates the data with the addition of an interfering competition from a fragmentation process from the unprotonated pyrimidine species. The last significant step in the cleavage reaction appears to be the breaking of the $\mathrm{C}-\mathrm{N}$ bond. Based on the pHdependence of the rate data, it is necessary that the most favorable state for the fragmentation step occurs when both the pyrimidine and thiazole are protonated on nitrogen. The positive pyrimidine promotes formation of the carbanion while the protonated thiazole provides a local proton source for the incipient carbanion.

\section{LEARNING MORE LESSONS}

Stewart Chan in our group has taken on further work in this project. Ab initio calculations can track the course of the fragmentation step. So far, working with some simplified structures, we find that the process is not leading to a singular pathway. He has also produced a number of new thiamin analogues that then react with benzaldehyde or derivatives. The electronic demand of the transition state can be estimated from the electronic characteristics of those materials that undergo fragmentation and those that do not.

\section{INTERMEDIATES IN BENZOYLFORMATE DECARBOXYLASE AND AVOIDING FRAGMENTATION}

Knowledge of the nonenzymic mechanism does lead us to considering the way the enzyme avoids fragmenting its cofactor. The loss of carbon dioxide from the intermediate generates the enamine. If a proton source is available, this will block the fragmentation process.

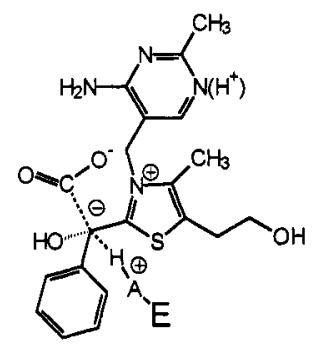

The concerted mechanism seems unlikely since it involves an over-coordinated central carbon atom. A stepwise process would most likely involve a thermodynamically favourable proton transfer to $\mathrm{C} 2 \alpha$ of the enamine from a Brønsted acid on the enzyme. If the conjugate base is weak, the fragmentation will not be accelerated.

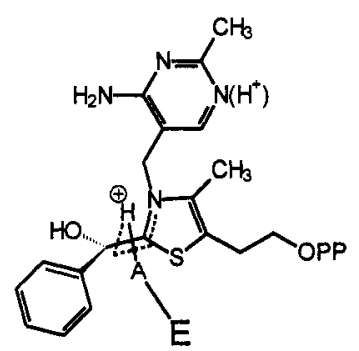

The enzyme would require a base to accept the hydroxyl proton from the incipient benzaldehyde species in order to release the cofactor. Once the proton from oxygen is lost, no rotations are necessary to achieve overlaps necessary for release of benzaldehyde. The catalytic mechanism for release of benzaldehyde should resemble that for other decarboxylases in which a carbonyl group is produced with expulsion of the ylide form of $\underline{1}$.(ref. 19,20 ) 


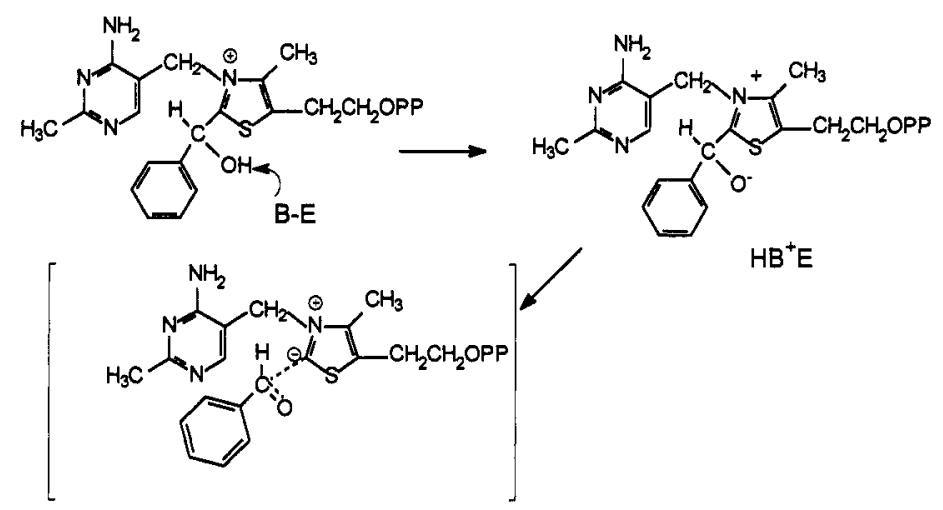

\section{CONCLUSION}

Physical organic chemistry has had a major impact on understanding the biochemical functions and catalytic properties of thiamin. Careful observation of thiamin in its nonnative habitat has also helped us test the principles of physical organic chemistry. It continues to be an exciting area for research.

\section{ACKNOWLEDGMENTS}

I thank my many coworkers for their valuable contributions to this project and the Natural Sciences and Engineering Council of Canada for continued support through an operating grant.

\section{REFERENCES}

1 R. R. Williams, A. E. Ruehle, J. Finkelstein, J. Am. Chem. Soc. 59, 526-529 (1937).

2 L. O. Krampitz, Thiamin Diphosphate and Its Catalytic Functions (Marcel Dekker, New York, 1970).

3 S. Mizuhara, P. Handler, J. Am. Chem. Soc. 76 (1954).

4 R. Breslow, J. Am. Chem. Soc. 79, 1762-1763 (1957).

5 R. Brelsow, Chem. Ind. (London), $893-894$ (1957).

6 R. Breslow, J. Am. Chem. Soc. 80, 3719-3726 (1958).

7 J. Crosby, G. E. Lienhard, J. Am. Chem. Soc. 92, 5707-5716 (1970).

8 R. Kluger, J. Chin, T. Smyth, J. Am. Chem. Soc. 103, 884-888 (1981).

9 M. I. Page, W. P. Jencks, Proc. Natl. Acad. Sci. U.S.A. 68, 1678 (1971).

10 R. Kluger, T. Smyth, J.Am. Chem. Soc. 103, 1214-1216 (1981).

11 R. Kluger, M. Brandl, J. Am. Chem. Soc. 108, 7828-7832 (1986).

12 F. J. Alvarez, J. Ermer, G. Huebner, A. Schellenberger, R. L. Schowen, J. Am. Chem. Soc. 113, $8402-9$ (1991).

13 D. Huhta, et al., Acta. Chem. Scand. 46, 778-788 (1992).

14 G. E. Lienhard, Science 180, 149-154 (1973).

15 R. Wolfenden, Accts. Chem. Res. 5, 10-18 (1972).

16 J. A. Gutowski, G. E. Liemhard, J. Biol. Chem. 251, 2863-2866 (1976).

17 R. Wolfenden, Mol. Cell. Biochem. 3, 207-211 (1974).

18 R. Kluger, G. Gish, G. M. Kauffman, J. Biol. Chem. 259, 8960-8965 (1984).

19 A. Turano, et al., J. Am. Chem. Soc. 104, 3089-3095 (1982).

20 W. Shin, D. Oh, C. Chae, T. Yoon, Journal of the American Chemical Society 115, 12238-12250 (1993).

21 Y. Lindqvist, G. Schneider, U. Ermler, M. Sundstrom, The EMBO Journal 11, 2373-2379 (1992). 
22 U. Nilsson, Y. Lindqvist, R. Kluger, and G. Schneider, FEBS Lett. 326, 145-148 (1993).

23 F. Dyda, et al., Biochemistry 32, 6165-6170 (1993).

24 Y. A. Muller, et al., Structure 1, 95-103 (1993).

25 M. Hasson, The Structure of Benzoylformate decarboxylase, H. Bisswanger, A. Schellenberger, Eds., Thiamin Pyrophosphate Biochemistry, Blaubeuren, Germany (in press, 1996).

26 M. W. Washabaugh, W. P. Jencks, Biochemistry 27, 5044-53 (1988).

27 F. G. Bordwell, A. V. Satish, F. Jordan, C. B. Rios, A. C. Chung, J. Am. Chem. Soc. 112, 792-797 (1990).

28 F. Jordan, Z. H. Kudzin, C. B. Rios, J. Am. Chem. Soc. 109, 4415-4416 (1987).

29 E. J. Crane, M. W. Washabaugh, Bioorg. Chem. 19, 351-368 (1991).

30 R. Kluger, J. F. Lam, C.-S. Kim, Bioorg. Chem. 21, 275-283 (1993).

31 J. A. Zoltewicz, G. Uray, Bioorg. Chem. 22, 1-28 (1994).

32 Y. Oka, S. Kishimoto, H. Hirano, Chem. Pharm. Bull. 18, 527-33 (1970).

33 L. J. Reynolds, G. A. Garcia, J. W. Kozarich, G. L. Kenyon, Biochemistry 27, 2217-2212 (1988).

34 L. J. Dirmaier, G. A. Garcia, J. W. Kozarich, G. L. Kenyon, J. Am. Chem. Soc. 108, 3149 (1986).

35 W. P. Jencks, Catalysis in Chemistry and Enzymology (McGraw-Hill, New York, 1969).

36 R. Kluger, J. F. Lam, J. P. Pezacki, C.-M. Yang, J. Am. Chem. Soc. 117, $11383-11389$ (1995).

37 J. F. Lam, Ph.D., University of Toronto (1995). 